\title{
Regular semigroups with the ideal retraction property
}

\author{
Xiaojiang Guo • Wenjuan Guo
}

Received: 23 April 2008 / Accepted: 6 August 2008 / Published online: 5 September 2008 (C) Springer Science+Business Media, LLC 2008

This article has been published OnlineFirst, but is withdrawn by the author.

X. Guo (凶)

Department of Mathematics, Jiangxi Normal University, Nanchang, Jiangxi 330022,

People's Republic of China

e-mail:xjguo@jxnu.edu.cn

W. Guo

College of Education, Jiangxi Normal University, Nanchang, Jiangxi 330022,

People's Republic of China 